\title{
Correction to: Examination of the M20D Auxin Conjugate Peptidase Family from Hornwort and Implications on the Evolution of the Tracheophytes
}

\author{
Edgar A. Medina ${ }^{1}$. Samuel Desind ${ }^{1} \cdot$ Abdulkader Hallak $^{1}$ - Abdullah Alhaddad ${ }^{1}$. John V. Smalley ${ }^{2}$. \\ James J. Campanella ${ }^{1}(1)$
}

Published online: 12 September 2021

(c) Springer Science+Business Media, LLC, part of Springer Nature 2021

\section{Correction to: Journal of Plant Growth Regulation https://doi.org/10.1007/s00344-021-10467-3}

The original version of this article unfortunately contained an error, and it has been corrected with this erratum.

The Supplementary Table 1 was originally published with the wrong format; it has now been replaced with the correct file.

Supplementary Information The online version contains supplementary material available at https://doi.org/10.1007/s00344-021-10479-z.
Publisher's Note Springer Nature remains neutral with regard to jurisdictional claims in published maps and institutional affiliations.

The original article can be found online at https://doi.org/10.1007/ s00344-021-10467-3.

James J. Campanella

james.campanella@montclair.edu

1 Department of Biology, Montclair State University, 1 Normal Ave, Montclair, New Jersey 07043, USA

2 Department of Biology and Horticulture, Bergen Community College, 400 Paramus Rd, Paramus, New Jersey 07652, USA 